\title{
'Sathkaara': an e-facility for optimising ICU bed usage
}

\author{
W.A.S. Sirichandra
}

University of Colombo School of Computing, Sri Lanka.

\section{S.O.K. Liyanage}

University of Colombo School of Computing, Sri Lanka.

\author{
W.V.S. Jayasinghe \\ University of Colombo School of Computing, Sri Lanka.
}

Dr. S.M.K.D. Arunatileka

University of Colombo School of Computing, Sri Lanka.

Dr. K.R.P. Chapman

District General Hospital, Chilaw, Sri Lanka.

Dr. N. Wijesooriya

Teaching Hospital, Ragama, Sri Lanka.

Contact e-mail address: wvsjayasinghe@gmail.com

eHealth Sri Lanka 2010,1(suppl.1):S37

DOI: http://dx.doi.org/10.4038/sljbmi.v1i0.3690

Only the Abstract is available

\begin{abstract}
Intensive Care Unit (ICU) is the most demanded ward for critical patients. Patients who need continuous monitoring and special life support are admitted to ICU. Most of the ICUs in the world have a problem of inadequate resources. Due to heavy cost of ICUs, in Sri Lanka, ICUs are insufficient and resources are unequally distributed. ICUs are often fully occupied because of the low bed strength which leads to patient transfers. Typically, existing procedure takes hours to find a vacant bed with adequate resources to treat the patient. It puts the patient in danger until he reaches the ICU of the receiving hospital. Poor clinical documentations and poor communication among inter hospital medical staff also badly affect the medication. This is where "Sathkaara" comes into action. This provides a real time web based system for the ICUs in hospital network to update the ICU bed and resource availability. Hence it has the ability to search for beds and resources which are at a distance.

Special equipment like CT and MRI scanners will require diagnosis, where the availability of this information is also critical. This will allow consultants to search for a hospital with necessary facilities quickly. The hospital can be informed on the requirement for using these equipment before transfering the patient. Details of doctors' qualifications and specialised areas in the ICU ward will be captured where this information could be referred to before transferring a patient. Ability to send information regarding a patient's clinical condition through electronic records to the receiving hospital allows the receiving hospital staff to prepare early before the patient arrives. "Sathkaara" ensures saving lives of critical patients through reducing the barriers in patient transfers and the maximum utilisation of the available ICU facilities, so that the patient will receive treatment without delays.
\end{abstract}

Keywords - ICU, low bed strength, patient transfers, CT, MRI 